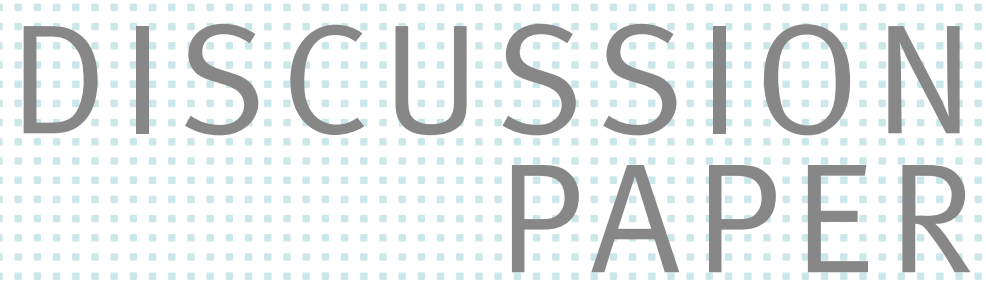

// ZAREH ASATRYAN, THUSHYANTHAN BASKARAN, PATRICK HUFSCHMIDT, AND ALEXANDER STÖCKER

\title{
Regional Favoritism and Human Capital Accumulation in Africa
}




\title{
Regional Favoritism and Human Capital Accumulation in Africa
}

\author{
Zareh Asatryan (ZEW Mannheim) \\ Thushyanthan Baskaran (University of Siegen, ZEW Mannheim)* \\ Patrick Hufschmidt (University of Siegen) \\ Alexander Stöcker (University of Siegen)
}

March, 2021

\begin{abstract}
We study the long-run implications of regional and ethnic favoritism in Africa. Combining geocoded individual-level survey data from the Demographic and Health Survey (DHS) with data on national leaders' birthplaces across 41 African countries, we explore the educational attainment of adults who were exposed to favoritism at various points during their life. We find that generic male respondents exposed to regional favoritism during their adolescence have higher educational attainment later in life. This higher human capital accumulated by men leads to more stable employment. For generic women, we observe no beneficial effects of regional favoritism. However, those women who belong to the same ethnic group as their national leader witness an increase in their educational attainment. These results indicate that regular inhabitants rather than only a narrow elite benefit from regional favoritism.
\end{abstract}

Keywords: Favoritism, human capital, gender discrimination, democracy, spatiality, Africa JEL codes: D73, J24, R11.

\footnotetext{
${ }^{*}$ Corresponding author: Thushyanthan Baskaran, Department of Economics, University of Siegen, Unteres Schloß 3, 57072 Siegen, Germany, Tel: +49(0)-271-740-3642, email: baskaran@vwl.uni-siegen.de. We gratefully acknowledge financial support from the German Research Foundation (DFG) within the Project "Regional Favoritism and Development" (Grant no. 423358188 / BA 496716-1). The usual disclaimer applies.
} 


\section{Introduction}

Political leaders regularly use public resources to favor some regions within their countries over others. Indeed, regional favoritism appears to be a global phenomenon, observable in one form or another in contexts as varied as Europe (Baskaran and Fonseca, 2020; Asatryan and Havlik, 2020), Asia (Do et al., 2016; Blundell and MaCurdy, 1999), or Africa (Burgess et al., 2015). One question that remains largely unexplored, however, is how favored regions make use of any additional resources obtained due to their connection to powerful politicians. Are the benefits of regional favoritism reaped by the general public in the favored regions or do they accrue only to a narrow elite? Do individuals continue to benefit from investments made during the time their region was favored even after connected politicians step down from power? Or do benefits evaporate quickly? Does it matter how old individuals were when their region was favored for their outcomes later in life? Are there differences across genders?

This paper studies these questions. We focus on the African continent and make use of micro-data from the Demographic and Health Surveys to explore the long-run implications of favoritism for inhabitants in favored regions. We rely in particular on the ability to geolocate DHS survey clusters, allowing us to identify whether a DHS respondent was living in the same place as the birthplace of a national leader at any point during her life. In addition, we measure whether a DHS respondent belongs to the same ethnicity as the national leader. We then explore how being geographically and ethnically connected to a national leader, and thereby potentially benefiting from, respectively, regional and ethnic favoritism, affects educational attainment. By exploring the implications of favoritism on educational attainment, our goal is to better understand how the resources required due to favoritism are used by the favored regions, who benefits, and whether benefits are merely consumed in the short-run or embodied by inhabitants in the form of human capital with corresponding implications for their welfare in the long-run.

An obvious methodological challenge is that (the inhabitants of) regions that are connected to national leaders might be systematically different than (inhabitants of) other regions. For example, national leaders might be more likely to originate from the wealthier parts of their respective countries. As such, comparing respondents from DHS clusters that were connected to a national leader with respondents from other unconnected DHS clusters might lead to biased results. To address this concern, we develop an identification strategy that exploits both between- and within-DHS cluster variation. In essence, we implement a difference-in-differences design where we compare respondents from the same DHS cluster who were born before and after a geographically connected leader had assumed power at the national 
level, while using respondents from DHS clusters that were never connected to a leader to account for temporal confounders.

We find that male respondents have higher educational attainment at the time the corresponding DHS survey was taken primarily if a connected leader had assumed power when they were between five and twelve years old. Exploring the labor market implications of the higher educational attainment of connected men, we observe that male respondents who were connected to a leader in their youth are more likely to have all-year employment, indicating that they are able to transform their higher human capital to more stable employment opportunities.

Women in favored regions, on the other hand, do not display higher educational attainment, independent of how old they were when they might have benefited from favoritism. The one exception are women who were coethnics of national leaders. These women witness an increase in educational attainment that is on average similar to the one observed for generic men.

This paper is primarily related to the evolving literature on regional favoritism. The seminal paper by Hodler and Raschky (2014) suggests that regions connected to a national leader exhibit more economic activity, as proxied by nighttime luminosity. Hodler and Raschky (2014) also show that favoritism appears to stop almost immediately after the connected leader steps down from power. Dreher et al. (2019) show that the allocation of Chinese Aid is subject to favoritism, and that favored regions appear to benefit in terms of local economic development, again measured by nighttime luminosity. Asatryan et al. (2021b) study the economic implications of mineral resource activity and finds that leaders' birth regions benefit unlike other non-mining region, but only in autocratic regimes. Asatryan et al. (2021a) document that firms located in favored regions are larger in size and are more productive, however these effects hold only in the non-tradeable sector and are temporary. A closely related literature focuses on the mechanisms by which favoritism might be executed, but limits the context to individual countries. For example, Burgess et al. (2015) show that Kenyan regions inhabited by co-ethnics of the president receive more road spending than other regions during periods of autocracy. During periods of democracy, favoritism appears to be enacted by less visible strategies, for example educational transfers. Similar evidence on the importance of regional favoritism is available for countries as varied as Germany (Baskaran and Fonseca, 2020), Vietnam (Do, 2017), Italy (Carozzi and Repetto, 2016) or across the regions of Europe (Asatryan and Havlik, 2020). On the other hand, Bandyopadhyay and Green (2019) find that connected leaders provide poorer quality roads to their home regions. Based on qualitative evidence, they argue that leaders channel resources to elites in their home regions at the expense of non-elites. 
Our paper contributes to this literature by shifting the focus onto individuals, the final recipients of favoritism, rather than focusing on the means of favoritism such as public spending or aggregate outcomes such as nighttime luminosity. While there is strong evidence that favored places contemporaneously benefit from having a connected leader in terms of luminosity or visible public goods such as roads, less is known whether such benefits indeed accrue to regular inhabitants and, if so, who specifically benefits and whether the benefits persist in some form after a connected leader has stepped down from power.

Our paper is also related to the literature on ethnic rather than regional favoritism. De Luca et al. (2018) and Dickens (2018) find that co-ethnic leaders allocate more resources to the homelands of their co-ethnics, as proxied by nighttime luminosity. Focusing on more specific outcomes, Theisen et al. (2020) find that ethnic favoritism contemporaneously reduces infant mortality. Franck and Rainer (2012) find that being ethnically connected to the national leader during childhood improves educational attainment and health outcomes. However, while ethnic and regional favoritism are related and might be difficult to distinguish in practice, the potential beneficiaries as well as their likely implications for local economic development are possibly different. In this paper, we disentangle the effects of regional and ethnic favoritism and also explore interaction effects between both.

Our paper is also related to the literature on the benefits of personal connections between individuals, notably businessmen, and political leaders. Focusing on the assumption and loss of power by individual leaders, various studies show that personal ties to national leaders comes with significant benefits for business leaders. For example, Acemoglu et al. (2018) show that street protests in Egypt against the Mubarak government reduced the stock prices of firms connected to the regime. Schoenherr (2018) finds similar evidence for Korea. Specifically, private firms with CEOs within the president's network are more likely to receive procurement contracts from state-owned enterprises. Quoc-Anh et al. (2015) and Acemoglu et al. (2016) present corresponding findings for the US. Our paper is related to this literature insofar that we explore whether benefits of political connections, and specifically regional favoritism, are indeed accrued only by a narrow elite or whether regular inhabitants are beneficiaries as well.

Finally, our paper is also related to the literature on the spatial implications of distributive politics. Neoclassical models of distributive politics derive that office-motivated politicians have strong incentives to allocate disproportionate public resources to electorally important geographies (Weingast et al., 1981), such as core, swing, or politically aligned districts (Cox and McCubbins, 1986; Cox, 2009; Albouy, 2013; Baskaran and Hessami, 2017). Our paper is distinct from this literature in that we focus on 
geographical distortions in the allocation of public resource due to leaders' intrinsic preference for her birthtown, rather than due to a opportunistic electoral considerations.

\section{Data}

\subsection{Archigos Leader Data}

We focus on regional ties to national leaders in this paper given the centralized political structures in Africa where national leaders have substantial influence over public policies (van de Walle, 2003; Posner, 2007). Following previous literature, we rely on the Archigos dataset to identify the identity and the start and end date of national leaders' terms across Africa (Goemans et al., 2016). Hodler and Raschky (2014) add to the Archigos database the birthplaces of national leaders and identify the respective latitude and longitude coordinates. We build on the Hodler and Raschky (2014) database and extend it up until 2015. Our final database on national leaders covers 366 leaders in Africa across 52 African countries who were in office during the period 1859-2015.

\subsection{DHS data}

\subsubsection{Sample}

To explore individual-level implications of favoritism, we assemble a dataset consisting of 137 individual DHS country surveys covering 42 African countries and spanning 33 years (1986-2016). The DHS is a well known nationally representative household survey with a large number of standardized questions, which enables us to pool individual surveys across countries and over time. The DHS provides various "recodes" of the survey responses, e. g. individual-level recodes, couple recodes, children recodes etc. Since we are interested in individual-level outcomes, we use the individual recode for women and men. In addition, the DHS provides in separate files information on the place of residence of respondents by means of geocodes (longitude and latitude coordinates) indicating the location of their DHS cluster.

The full sample of DHS surveys we assemble covers 1,708,290 respondents. We then plot the geolocation of the 55,157 DHS clusters with available geocodes for each survey on a map of Africa. Next, we identify whether a cluster was within a 10km buffer surrounding a leader's birth place in a given year. We refer to these clusters as treated clusters and to the remaining clusters as untreated clusters. We also experiment with $5 \mathrm{~km}$ and $20 \mathrm{~km}$ buffers. ${ }^{1}$ In Figure 1, those clusters that fall within the 10km buffers

\footnotetext{
${ }^{1}$ See Asatryan et al. (2021a) for similar evidence of favoritism across distance to leader's birthplace but for firms. They show that the effects are strongest in a $10 \mathrm{~km}$ radius and die out after about 100km away from the leader's birthplace.
} 
around leaders' birthplaces, indicated by green circles, are the treated clusters and are indicated by green dots. The untreated clusters, i. e., those that fall outside the green circles, are indicated by yellow dots.

Since we are interested in the effect of favoritism experienced at different points in life, we will only focus on all respondents who have always lived in the same place of residence. We also drop DHS clusters that were intermittently treated. ${ }^{2}$ Our final estimation sample includes 520,862 individuals located in 35,743 DHS clusters across 41 African countries and covers 91 individual surveys conducted over 29 years.

We classify all DHS respondents in these clusters who were alive (i. e., not yet born) when the leader was in power as treated and refer to them as treated individuals. We also identify the specific age range during which a respondent was treated, i. e., whether or not at any given age a respondent had a geographically connected national leader in power.

Of the 35,743 DHS clusters in the final sample, 914 were connected to a national leader during the sample period. 12,853 respondents in our sample have continuously lived in these treated clusters. Of these, 8,264 are treated individuals as per our definition above (i. e., respondents who were born before or during the tenure of a connected leader). Accordingly, 4,589 respondent are untreated individuals in treated clusters (i. e., these are the respondents born after the connected leader had stepped down from power).

Table 1 includes further descriptive statistics on the sample. As the DHS emphasizes female respondents, the number of women in our final sample is larger than the number of men. The total number of women is 397,645 while the number of men is 123,217 . Data on men is also available only for 32 of the 41 countries. Reflecting this distribution across genders, the number of women living in treated clusters is 10,058 while the number of men is 2,795 . The number of treated women living in treated clusters is 6,634 and of treated men is 1,630 . The average age of respondents at the time of the DHS interview is 28.28 years. The average age of treated individuals is 30.53 years, while the average age of untreated individuals in treated clusters is 21.34 years. Figure 3 shows the age distribution of respondents both in the treated clusters as well as in the untreated clusters.

\subsubsection{Data on educational attainment}

The main outcome variable we explore is educational attainment as proxied by the number of years a respondent went to school. There are various channels, both indirect and direct, as to why educational

\footnotetext{
2 That is, DHS clusters with at least two different national leaders who held power during non-consecutive terms (or a national leader who re-assumed power after initially stepping down).
} 
attainment might improve due to regional favoritism. Among the direct channels, an obvious one is that a connected leader allocates additional educational resources to favored regions, ranging from physical investments such as the construction of schools or provision of materials or an expansion in personnel, notably teachers. A more indirect channel is that a broader expansion in economic development allows parents to keep children longer in school or that an expected expansion in demand for more qualified labor motivates children to acquire further education. Previous research such as Hodler and Raschky (2014) and Burgess et al. (2015) provide evidence for the potential relevance of both direct and indirect channels.

Table 2 collects summary statistics on educational attainment for different subsamples. The average years of education across all respondents from the various waves is 4.3 years. Disaggregating by gender, we observe expected patterns given that African countries typically conform to traditional gender roles: men have on average about 1.3 years of education more than women.

We also observe several patters across treated and untreated clusters and respondents. Comparing untreated respondents living in clusters that were ever connected to a national leader, i e. untreated respondents in treated clusters, with untreated respondents from untreated clusters, we observe that the former have about two more years of education. Finally, comparing treated respondents with untreated respondents in treated clusters, we observe that the former are slightly more educated (about 0.6 years).

These last set of descriptive statistics suggest that national leaders on average originate from regions that are more developed than the remainder of their country, at least when proxied by educational attainment. In addition, that treated respondents within treated clusters have more years of education provides descriptive evidence that being connected to a national leader has benefits in terms of educational opportunities. Naturally, we explore below whether this is indeed the case in a more elaborate empirical framework.

\section{Empirical strategy and specification}

Our aim is to explore how being connected to a national leader affects the educational attainment of DHS respondents. As discussed, respondents living in places connected to national leaders may be different than those living elsewhere in the country. For example, national leaders may be more likely to originate from regions where inhabitants are richer and more educated. To address this concern about selection, we implement an identification strategy centered around the idea of comparing individuals from the 
same region (specifically from the same DHS cluster) who were born after a leader had stepped down from power with individuals who were born earlier.

While the positive effect of geographic connections may linger on for some time after a leader has stepped down from power, these effects will plausibly wane over time if active regional favoritism stops after a connected leader steps down from power. Accordingly, individuals born after a leader had stepped down form power should benefit, on average, less from favoritism than those born earlier. At the same time, any time-constant differences between individuals living in different regions are accounted in our design through the inclusion of DHS cluster fixed effects as DHS clusters are survey-specific.

However, treated individuals are systematically older than non-treated individuals in this design. To address this imbalance, we always control for the age of a respondent at the time of the DHS interview. Thereby, we essentially compare treated and untreated respondents of similar age who differ in their treatment status only due to the fact that they live in different clusters (and which consequently were treated at different points in time).

We also control for birth year fixed effects to account for cohort-specific trends. That is, respondents from untreated clusters provide the counterfactual for treated respondents who were born in the same year with respect to global trends in educational attainment. In general, cohorts born later tend to have higher educational attainment as adults.

In view of the above discussion, our baseline specification is as follows:

$$
y_{i}=\alpha_{c}+\gamma_{t}+\beta \text { Connected } \text { Leader }_{i}+\gamma \text { Age }_{i}+\varepsilon_{i},
$$

where $y_{i}$ is the educational attainment of individual $i$, proxied by years of education. We always estimate this model for female and male subsamples as the effects of favoritism might be systematically different between genders.

Connected Leader ${ }_{i}$ is a dummy that is 1 if a respond was connected to a leader at some point during her life. $\alpha_{c}$ are fixed effects for all 35,743 DHS clusters. As discussed above, since DHS clusters are survey-specific, these fixed effects implicitly control for interview-year as well as country-specific effects. $\gamma_{t}$ are birth year fixed effects. $\varepsilon_{i}$ is an individual-specific error. For the hypothesis tests below, we always assume $\varepsilon_{i}$ is clustered at the country-specific DHS wave level, i. e., at the level of individual surveys. 
While Equation 1 is our initial specification, we also estimate variants that accounts for the specific age range when a respondent was first exposed to a connected leader: favoritism is likely to matter more for education if respondents experience it in their childhood or adolescence rather than later in life.

First, we estimate a model that distinguishes between respondents who were treated in their youth and who were treated later by defining the age of twelve as the cutoff. That is, we group respondents according to whether they were treated for the first time before they were twelve or later. The model is as follows:

$$
\begin{aligned}
y_{i}= & \alpha_{c}+\gamma_{t}+\beta_{1} \text { Connected Leader before age } 12_{t, i} \\
& +\beta_{2} \text { Connected Leader after age } 12_{t, i}+\gamma \mathrm{Age}_{i}+\varepsilon_{i} .
\end{aligned}
$$

Second, we estimate a more disaggregated model that splits respondents into four groups according to their age at which they first became connected to a leader. The model is as follows:

$$
y_{i}=\alpha_{c}+\gamma_{t}+\sum_{t} \beta_{t} \text { Connected Leader at } \mathrm{Age}_{t, i}+\gamma \mathrm{Age}_{i}+\varepsilon_{i},
$$

where Connected Leader at $\mathrm{Age}_{t}$ is a set of dummies indicating the following age ranges: before age 5, between 5-12 years, between 12-18 years, and after 18 years. To be clear, these dummies are defined, in line with our approach when distinguishing between respondents connected before and after they were twelve, such that only the earliest age range with a connection is set to 1 and all subsequent age ranges are set to 0 . For example, a respondent who had a connected leader when she was e. g. three years old would have a value of 1 for the dummy covering the age range up to 5 years but 0 for all subsequent age ranges (even if she remained connected during these later stages of her life). A respondent who was connected at the age of 10 would have a value of 0 for the dummy for the age range up to 5 years, 1 for the dummy covering the age range between 5-12 years, and 0 for all subsequent age ranges.

\section{Results}

\subsection{Main results}

We start by exploring the effect of having been exposed to a connected leader on educational attainment. Table 3 collects the results. A first finding is that there is significant heterogeneity across genders. While generic women exposed to connected leaders display no improved educational attainment at the 
time of the DHS interview, generic men who were treated have on average 0.41 years more education than untreated men. This estimate is significant at the 5\% level and amount to a nearly $10 \%$ increase in education relative to the sample mean.

Disaggregating by the various age ranges, we find that the improved educational attainment of men is due to those who were first exposed to a connected leader when they were relatively young. That is, Model (5) indicates that the treatment effect is only significant for men who were treated for the first time when they were younger than twelve. Model (6) narrows down the relevant age range further. Men first exposed to regional favoritism between five and twelve years have about one more year of education than untreated men. The effect for men first exposed before they were five, while still positive, is only 0.28 years and insignificant. In contrast to men, we fail to find a positive treatment for women at any age range.

\subsection{Robustness tests}

\subsubsection{Flexible control for individuals' age}

The identification strategy relies ultimately on a cutoff based on the age of respondents: we compare individuals born before and after a connected leader stepped down from power. Accordingly, as discussed above, the treated individuals within each treated DHS clusters are systematically older than the untreated individuals, which may give rise to imbalances in outcomes even in the absence of treatment.

We address this concern in the baseline regressions by including a linear term for age. However, it is advisable to explore the robustness of the results with more flexible controls for the age of a respondent at the time of the DHS interview. Thus, we report results where we add up to a cubic polynomial of age to the baseline specification. We report the estimated treatment effect in column (1)-(2) of Table 5. The results are similar to the baseline estimates. In particular, we find a significantly positive effect for men who were connected when they were between five and twelve years, but not for other men. We find no significant effects for women.

\subsubsection{Varying the size of buffers to define treated clusters}

In the baseline sample, we assume that all DHS clusters within a buffer of $10 \mathrm{~km}$ are treated. In this section, we explore the robustness of the results to this choice. Instead of a buffer of $10 \mathrm{~km}$ to delineate treated from untreated cluster, we re-estimate the baseline specifications using a buffer size of $5 \mathrm{~km}$ and 
of $20 \mathrm{~km}$, respectively. Naturally, the number of treated clusters and treated individuals is accordingly either smaller or larger than in the baseline specification.

The results for a buffer of $20 \mathrm{~km}$ are collected in column (3)-(4) and for a buffer of $5 \mathrm{~km}$ in column (5)(6) of Table 5. We find that the results are generally similar to the baseline estimates. More specifically, the effect for male respondents first connected to a leader when they were between five and twelve years is of similar size as in the baseline regressions and significant when using a buffer of $5 \mathrm{~km}$. When using a wider buffer of $20 \mathrm{~km}$, we still observe a relatively large effect for these men, but the effect turns insignificant. This particular finding suggests that the beneficial effects of regional favoritism are relatively local.

\subsubsection{Different sample size for women and men}

One reason why the results may be different between women and men is that the DHS has generally a better coverage of female respondents. One implication of this focus is that the number of DHS clusters included in our regressions differs between the male and female subsamples as there are several clusters that only have information on female respondents (however there are also some, but very few, clusters that only information on male respondents). To explore whether our results are driven by the different number of clusters, we re-estimate the baseline specification with only those DHS clusters that have information on both women and men. We find that the results collected in column (7)-(8) of Table 5 are similar to the baseline estimates.

\subsubsection{Respondents born in treated clusters shortly after treatment had ended}

Any positive effects of favoritism may linger on for a few years after the connected leader has stepped down from power. Accordingly, the baseline estimates might be lower bounds given that individuals who have been treated are classified as part of the control groups. To explore this issue, we re-estimate the baseline specifications after including a separate dummy for individuals in treated clusters who were born within five years after a connected leader had stepped down from power. The results are collected in column (9)-(10) of Table 5. We again find that the estimates are very similar to the baseline estimates. Men benefit from regional favoritism when they were treated in their youth while women do not benefit irrespective of when they were treated. 


\subsubsection{Placebo treatments}

We now explore the robustness of the baseline estimates using placebo regressions. If we had obtained the baseline results only by chance, randomly assigning treatments to non-treated respondents should produce similarly significant coefficients. Instead, if random assignment of treatment would result in coefficient estimates that are centered around zero, it is likely that the baseline estimates imply that favoritism has substantive effects.

We hence re-estimate the baseline regressions for the average effect of favoritism using placebo treatments. We proceed as follows. First, we drop all 914 treated clusters from the sample. Then we randomly draw 8,264 untreated individuals from this sample and assign placebo treatment to each of these respondents. We then re-estimate the baseline specifications.

For each specification, we estimate 100 models and plot the cumulative distribution of the estimated coefficients in Figure 4. The coefficient estimates are indicated by blue dots. We observe that the placebo estimates are, as expected, centered around 0. In addition, none of the placebo coefficients is of similar magnitude than the treatment effect observed for men. This indicates that the higher educational attainment of treated men is indeed due to favoritism.

\section{Extensions}

\subsection{Length of treatment and non-linear effects}

The results above indicate that male respondents who were connected for the first time between five and twelve years have higher educational attainment. What is surprising is that respondents who were connected for the first time when they were less than five have a much smaller treatment effect. Some of these respondents have continued to benefit from favoritism when they aged and surpassed the age of five.

This pattern of results indicates the existence of non-linearities. Respondents who are connected for too long may have worse outcomes than those who were connected only for a short amount of time. This is possible if leaders invest first in educational opportunities and other "productive" public goods in their home regions, but then focus on more consumptive expenditures as they continue to stay in power, thereby crowding out incentives of respondents to acquire further education.

To explore this hypothesis, we estimate the following specification. We create a variable measuring the share of years a respondent was treated between her (i) birth and when she turned twelve years 
and (ii) between her fifth and her twelfth birthday. We then estimate a quadratic specification with educational attainment as the dependent variable:

$$
y_{i}=\alpha_{c}+\gamma_{t}+\beta \text { Share of years treated } i+\text { Share of years treated }_{i}^{2}+\gamma \mathrm{Age}_{i}+\varepsilon_{i} .
$$

The results are collected in Table 4. We indeed find evidence for a non-linear treatment effect, both for men and for women. Respondents have higher educational attainment when they were connected only for a short amount of time. Respondents who were connected for much of their entire childhood, on the other hand, have a treatment effect that is close to 0 . This indicates that persistent favoritism may have harmful even if unintended consequences. This particular specification also shows that women might benefit from favoritism as well, but that their benefits are substantially smaller than those of men and therefore evaporate more quickly if they are connected for too long to a national leader.

\subsection{Favoritism under democracy}

Research suggests that institutional constraints affect the behavior of political leaders. In particular, democracy and protections of civil liberties have been shown to limit leaders' ability to use public funds to pursue their parochial goals (Fearon, 1999; Besley and Reynal-Querol, 2011; Burgess et al., 2015). Accordingly, if and how inhabitants of connected regions benefit from regional favoritism likely depends on whether their country was a democracy when the connected leader was in power.

To explore possible heterogeneity in the impact of regional favoritism, we estimate a specification where we indicate whether a connected respondent was living in a democracy when she might have started to benefit from favoritism. We use the revised combined Polity IV score provided by Teorell et al. (2010) to define democracy. Specifically, we recode this variable such that is bounded between 0 (full autocracy) and 1 (full democracy).

We relate the level of democracy when a respondent was five to educational attainment. We focus on the level of democracy at age five as our previous results for regional favoritism indicate that it are respondents who were connected to a national leader when they were between five and twelve who have higher educational attainment as adults.

The empirical model hence is as follows:

$$
y_{i}=\alpha_{c}+\beta_{1} \text { Connected Leader }_{i}+\beta_{2} \text { Connected Leader }_{i} \times \text { Polity }_{i, t}+\delta \text { Polity }_{i, t}+\gamma \text { Age }_{i}+\varepsilon_{i},
$$


with Polity ${ }_{i, t}$ a continuous variable between 0 and 1 indicating the level of democracy in a respondent's country when she was five years old. Note that we include the Polity variable as well as its interaction with the dummies indicating regional favoritism in this specification.

The results are collected in Table 8. We find some evidence that democracy weakens the effect of favoritism. We observe a significantly negative interaction effect for women who were ever connected to a national leader (Model 1), indicating that women might be even disadvantaged by regional connections to a national leader if their country was a democracy in their youth. For men, we also observe a negative, albeit insignificant and relatively small, interaction effect when we interact the level of democracy with the dummy for connections with a national leader at any point during the respondent's live (Model 4).

When we focus on the more disaggregated Model (6), we obtain clearer evidence for a diminishing effect of democracy on regional favoritism among men and women. The interaction effect between the polity variable and the dummy for connections between the age of five and twelve is negative and, while statistically insignificant, with -1.038 almost as large as the main treatment effect for men. For women, the interaction effect is -1.022 and thus similarly large as for men. Overall, these results suggest that favoritism is weaker in democratic settings.

\subsection{Regional and ethnic favoritism}

Previous evidence suggest that besides regional favoritism, leaders might also engage in ethnic favoritism (De Luca et al., 2018; Franck and Rainer, 2012). In general, it is difficult to differentiate between regional and ethnic favoritism after the fact as ethnic groups are often concentrated in specific regions. That is, improvements in educational attainment in a leader's birth region might come about not because the leader aims to favor her birth region but rather her ethnic group, which only happens to be concentrated in her birth region.

Since most DHS surveys include the ethnicity of DHS respondents, we can explore whether our results are driven by regional or ethnic favoritism, and if there are any interactions between both. To do so, we appended to the basic Archigos database information on the ethnicity of national leaders. We then compare the ethnicity of national leaders with that of DHS respondents and define a dummy which is one if a respondent had a coethnic in power when she was five years old. ${ }^{3}$ We also construct an interaction variable between regional and ethnic favoritism to explore whether inhabitants of a leader's

\footnotetext{
${ }^{3}$ The names of ethnic groups are not consistent across DHS surveys even for individual countries. We thus first use a string-based matching approach with high tolerance and then check each of the matched ethnic groups one by one.
} 
birth region benefit more or less if they are also coethnics of the leader. The empirical specification we estimate is as follows:

$$
\begin{aligned}
y_{i}= & \alpha_{c}+\beta_{1} \text { Connected Leader }_{i}+\beta_{2} \text { Connected Leader }_{i} \times \text { Same ethnicity }_{i, t} \\
& +\delta \text { Same ethnicity }_{i, t}+\gamma \text { Age }_{i}+\varepsilon_{i} .
\end{aligned}
$$

As in the specifications for democracy, we focus on ethnic connections at age five as our previous results for regional favoritisms indicate that it is particularly effective when respondents were between five and twelve years.

The results of these specifications are reported in Table 7. The first result we observe is that across all models, ethnic connections as such have an insignificant effect on educational attainment. There are also no significant interaction effects between regional and ethnic favoritism for men. However, there are significant interaction effects between regional and ethnic favoritism for women.

In Model (1), we interact the ethnic favoritism dummy with the dummy for whether a respondent was ever regionally connected to a national leader. We find that women benefit more from regional favoritism when they are ethnically connected (at age five) to a national leader. The aggregate size of the effect of regional favoritism for women who are also ethnically connected $(0.320)$ is similar to that for generic men found in the baseline specifications in Table 3 (0.410). In Model (2), we include an interaction between ethnic connections and the dummy for regional favoritism before the age of twelve. We again observe that ethnically connected women benefit more from regional favoritism, even though the aggregate effect is only 0.102 in this specification. Finally, in Model (3), we include an interaction between the dummy for regional favoritism between the ages of five and twelve and the dummy for ethnic favoritism. We again observe a significant and large interaction effect, with the aggregate effect (1.346) again of similar size as the effect for generic men.

Overall, these results suggest that women might benefit from regional favoritism as well. However, the benefits are far more focused than for men and accrue only to coethnics. While speculative, this finding suggests that educational resources are allocated in a more cautious and selective fashion to women.

\subsection{Favoritism and employment outcomes}

We now explore whether the higher educational attainment obtained by men who had benefited from favoritism translates to better occupational outcomes. It is also possible that women have better occupa- 
tional outcomes when they were treated, despite no improvements in their formal educational attainment. For this, we focus on the question whether respondents have all-year employment. All-year employment is arguably related to more stable and productive occupations, which in turn require higher educational attainment.

We hence estimate the baseline specifications after replacing the outcome variables. In Table 6, we collect the results for all year employment. While the results are slightly weaker than for educational attainment in terms of statistical significance, we find that in particular men who were connected when they were between five and twelve years are noticeably more likely to have all year employment. This is in line with our findings for educational attainment and suggest that educational attainment increases human capital for men and thereby improves their labor market prospects.

\section{Conclusion}

In this paper, we explore whether individuals exposed to regional favoritism continue to display better outcomes as adults. We find that favoritism has positive effects on the educational attainment of men living in favored regions. This higher educational attainment has positive consequences for occupational opportunities. For women, the results are more varied. While women who are regionally connected to national leaders do not benefit in general, those women who are also ethnically connected witness an increase in educational attainment that is of similar magnitude as the increase for generic men. We also find that generic women in favored regions might even witness a decrease in their educational attainment if their country was a democracy when they were geographically connected to a national leader.

These findings suggest that favoritism benefits the general public rather than only a narrow elite: it is widespread enough for the effects to be visible among regular respondents of the DHS surveys. However, the benefits are genereally stornger in non-democratic settings. Favoritism also appears to have heterogeneous effects across genders. While the reasons for the discrepancy across genders are unclear at this point, we speculate that it can be explained by conformity with traditional gender roles, with men perceived as breadwinners and women as caretakers of the household. Given the necessity of education for men to conform to the role as breadwinners, it might be difficult to exclude specific men, notably those who do not belong to the same ethnicity of the national leader, when educational opportunities are expanded due to regional favoritism. On the other hand, it might be possible for a leader to be more judicious when allocating educational resources to women as public demands for ethnically unbiased educational opportunities might be lower when it comes to them. 
Overall, this paper shows that regional favoritism, while arguably leading to allocations of public resources according to non-economic criteria, must not necessarily be perceived as exclusively wasteful. Within the favored regions, these additional resources can have positive implications. On the other hand, there are heterogeneous effects, in particular across genders. In any case, for a full normative evaluation, we must also assess what else would have been done with these resources if they had not been allocated to connected regions. Whether they would have been used more productively if regional favoritism were not possible or whether they would have been wasted or allocated to the benefit of a few elites is an open question.

\section{References}

Acemoglu, D., Hassan, T. A., and Tahoun, A. (2018). The power of the street: evidence from Egypt's Arab Spring. Review of Financial Studies, 31:1-42.

Acemoglu, D., Johnson, S., Kermani, A., and Kwak, J. (2016). The value of connections in turbulent times: Evidence from the United States. Journal of Financial Economics, 121:368-391.

Albouy, D. (2013). Partisan representation in congress and the geographic distribution of federal funds. Review of Economics and Statistics, 95(1):127-141.

Asatryan, Z., Baskaran, T., Birkholz, C., and Gomtsyan, D. (2021a). Favoritism and firms: Micro evidence and macro implications. ZEW Discussion Paper 21-031.

Asatryan, Z., Baskaran, T., Birkholz, C., and Hufschmidt, P. (2021b). Regional redistribution of mineral resource wealth in Africa. ZEW Discussion Paper 21-032.

Asatryan, Z. and Havlik, A. (2020). The political economy of multilateral lending to European regions. The Review of International Organizations, 15(3):707-740.

Bandyopadhyay, S. and Green, E. (2019). Roads and regional favoritism in sub-Saharan Africa. LSE International Development Working Paper 19-195.

Baskaran, T. and Fonseca, M. L. (2020). Appointed public officials and local favoritism: evidence from the German states. Mimeo (University of Siegen).

Baskaran, T. and Hessami, Z. (2017). Political alignment and intergovernmental transfers in parliamentary systems: evidence from germany. Public Choice, 171:75-98. 
Besley, T. and Reynal-Querol, M. (2011). Do democracies select more educated leaders? American Political Science Review, 105:552-566.

Blundell, R. and MaCurdy, T. (1999). Labor supply: a review of alternative approaches. Handbook of Labor Economics.

Burgess, R., Jedwab, R., Miguel, E., Morjaria, A., and Padro i Miquel, G. (2015). The value of democracy: Evidence from road building in Kenya. American Economic Review, 105(6):1817-1851.

Carozzi, F. and Repetto, L. (2016). Sending the pork home: Birth town bias in transfers to Italian municipalities. Journal of Public Economics, 134:42-52.

Cox, G. W. and McCubbins, M. D. (1986). Electoral politics as a redistributive game. Journal of Politics, pages $370-389$.

Cox, W. G. (2009). Swing voters, core voters, and distributive politics. In Shapiro, I., Stokes, S. C., Wood, E. J., and Kirshner, A. S., editors, Political representation, pages 342-357. Cambridge University Press, Cambridge, UK.

De Luca, G., Hodler, R., Raschky, P. A., and Valsecci, M. (2018). Ethnic favoritism: An axiom of politics? Journal of Development Economics, 132:115-129.

Dickens, A. (2018). Ethnolinguistic favoritism in African politics. American Economic Journal: Applied Economics, 10:370-402.

Do, Q.-A. (2017). One mandarin benefits the whole clan: hometown favoritism in an authoritarian regime. American Economic Journal: Applied Economics, 9:1-29.

Do, Q.-A., Nguyen, K.-T., and Tran, A. (2016). One mandarin benefits the whole clan: Hometown favoritism in an authoritarian regime.

Dreher, A., Fuchs, A., Hodler, R., Parks, B. C., Raschky, P. A., and Tierney, M. J. (2019). Is favoritism a threat to Chinese aid effectiveness? A subnational analysis of Chinese development development projects. Kiel Working Paper.

Fearon, J. D. (1999). Electoral accountability and the control of politicians: selecting good types versus sanctioning poor performance. In Przeworski, A., Stokes, S. C., and Manin, B., editors, Democracy, Accountability, and Representation, pages 55-97. Cambridge University Press. 
Franck, R. and Rainer, I. (2012). Does the leader's ethnicity matter? Ethnic favoritism, education, and health in Sub-Saharan Africa. American Political Science Review, 106(2):294-325.

Goemans, H. E., Gleditsch, K. S., and Chiozza, G. (2016). Archigos: A data set on leaders 1875-2015, version 4.1 .

Hodler, R. and Raschky, P. (2014). Regional favoritism. Quarterly Journal of Economics, 129(2):9951033.

Posner, D. N. (2007). Regime change and ethnic cleavages in Africa. Comparative Political Studies, 40:1302-1327.

Quoc-Anh, D., Lee, Y. T., and Nguyen, B. D. (2015). Political connections and firm value: evidence from close gubernatorial elections. Mimeo.

Schoenherr, D. (2018). Political connections and allocative distortions. Journal of Finance, forthcoming.

Teorell, J., Samanni, M., Charron, N., Holmberg, S., and Rothstein, B. (2010). The quality of government dataset, version 27May10. University of Gothenburg: The Quality of Government Institute. http://www.qog.pol.gu.se.

Theisen, O. M., Strand, H., and Ostby, G. (2020). Ethno-political favouritism in maternal health care service delivery: Micro-level evidence from sub-saharan Africa, 1981-2014. International Area Studies Review, 13:1-25.

van de Walle, N. (2003). Presidentialism and clientelism in Africa's emerging party systems. ournal of Modern African Studies, 41:297-321.

Weingast, B., Shepsle, K., and Johnsen, C. (1981). The political economy of costs and benefits: a neoclassical approach to distributive politics. Journal of Political Economy, 89(4):642-664. 
Table 1: Characteristics OF DHS SAMPLE

\begin{tabular}{llll}
\hline Panel A: Full vs. final sample & & \\
& Full sample & & Final sample \\
\cline { 2 - 2 } Countries & 42 & 41 \\
Surveys & 137 & 96 \\
DHS clusters & 55,157 & 35,743 \\
Respondents & $1,708,290$ & 520,862 \\
\hline
\end{tabular}

Panel B: Treated vs. untreated clusters

\begin{tabular}{llll} 
& \multicolumn{1}{c}{ Treated } & & Untreated \\
\cline { 2 - 2 } DHS clusters & 914 & 34,829 \\
Respondents & 12,853 & 508,009 \\
Women & 10,058 & 387,587 \\
Men & 2,795 & 120,422 \\
Average age & 27.25 & 28.30 \\
\hline
\end{tabular}

Panel C: Treated vs. untreated individuals in treated DHS clusters

\begin{tabular}{llll} 
& Treated & & Untreated \\
\cline { 2 - 2 } Respondents in treated clusters & 8,264 & & 4,589 \\
Women in treated clusters & 6,634 & 3,424 \\
Men in treated clusters & 1,630 & 1,165 \\
Average age in treated clusters & 30.53 & 21.34 \\
\hline
\end{tabular}

This table provides descriptive information on the main sample.

Table 2: SUMMARY STATISTICS ON RESPONDENTS' EDUCATION

\begin{tabular}{llll}
\hline & & & \\
& Mean & Std. Dev. & N \\
\hline All respondents & 4.230 & 4.300 & 520370 \\
All female respondents & 3.910 & 4.270 & 397331 \\
All male respondents & 5.264 & 4.234 & 123039 \\
Treated respondents (in treated clusters) & 6.747 & 4.925 & 8254 \\
Untreated respondents (in treated clusters) & 6.149 & 4.469 & 4578 \\
Untreated respondents (in untreated clusters) & 4.172 & 4.271 & 507538 \\
\hline Notes:
\end{tabular}

Notes: This table collects summary statistics on the main outcome variables for different subsamples of DHS respondents. 
Table 3: CONNECTED LEADERS AND EDUCATIONAL ATTAINMENT

\begin{tabular}{|c|c|c|c|c|c|c|}
\hline \multirow[b]{3}{*}{ Dep.Var: Years of education } & \multicolumn{3}{|l|}{ Women } & \multicolumn{3}{|l|}{ Men } \\
\hline & (1) & (2) & (3) & (4) & (5) & (6) \\
\hline & & & & & & \\
\hline \multirow[t]{2}{*}{ Connected leader } & -0.239 & & & $0.410^{* *}$ & & \\
\hline & $(0.262)$ & & & $(0.177)$ & & \\
\hline \multirow[t]{2}{*}{ Connected leader, younger than 12} & & -0.236 & & & $0.428^{* *}$ & \\
\hline & & $(0.260)$ & & & $(0.184)$ & \\
\hline \multirow[t]{2}{*}{ Connected leader, older than 12} & & -0.291 & & & 0.303 & \\
\hline & & $(0.473)$ & & & $(0.392)$ & \\
\hline \multirow[t]{2}{*}{ Connected leader, younger than 5} & & & -0.275 & & & 0.275 \\
\hline & & & $(0.284)$ & & & $(0.195)$ \\
\hline \multirow[t]{2}{*}{ Connected leader, years 5-12 } & & & -0.040 & & & $1.009 * * *$ \\
\hline & & & $(0.417)$ & & & $(0.378)$ \\
\hline \multirow[t]{2}{*}{ Connected leader, years $12-18$} & & & -0.200 & & & 0.165 \\
\hline & & & $(0.541)$ & & & $(0.420)$ \\
\hline \multirow[t]{2}{*}{ Connected leader, older than 18} & & & -0.350 & & & 0.530 \\
\hline & & & $(0.504)$ & & & $(0.538)$ \\
\hline Control for Age & $\checkmark$ & $\checkmark$ & $\checkmark$ & $\checkmark$ & $\checkmark$ & $\checkmark$ \\
\hline DHS Cluster FE & $\checkmark$ & $\checkmark$ & $\checkmark$ & $\checkmark$ & $\checkmark$ & $\checkmark$ \\
\hline Birth year FE & $\checkmark$ & $\checkmark$ & $\checkmark$ & $\checkmark$ & $\checkmark$ & $\checkmark$ \\
\hline Countries & 41 & 41 & 41 & 32 & 32 & 32 \\
\hline Clusters & 31878 & 31878 & 31878 & 18561 & 18561 & 18561 \\
\hline $\mathrm{N}$ & 395718 & 395718 & 395718 & 120424 & 120424 & 120424 \\
\hline
\end{tabular}

Table 4: CONNECTED LEADERS AND EDUCATIONAL ATTAINMENT, NONLINEAR EFFECTS OF TREATMENT

\begin{tabular}{|c|c|c|c|c|}
\hline \multirow[b]{3}{*}{ Dep.Var: Years of education } & \multicolumn{2}{|l|}{ Women } & \multicolumn{2}{|l|}{ Men } \\
\hline & (1) & (2) & (3) & (4) \\
\hline & & & & \\
\hline \multirow[t]{2}{*}{ Share of years treated, $0-12$ years } & 1.190 & & $3.323 * * *$ & \\
\hline & $(0.801)$ & & $(1.030)$ & \\
\hline \multirow[t]{2}{*}{ Share of years treated, $0-12$ years ${ }^{2}$} & $-1.816^{*}$ & & $-4.245^{* * *}$ & \\
\hline & (1.066) & & $(1.330)$ & \\
\hline \multirow[t]{2}{*}{ Share of years treated, 5-12 years } & & 0.928 & & $3.075^{* *}$ \\
\hline & & $(0.914)$ & & $(1.474)$ \\
\hline \multirow[t]{2}{*}{ Share of years treated, 5-12 years ${ }^{2}$} & & -1.470 & & $-3.476^{* *}$ \\
\hline & & $(1.070)$ & & (1.619) \\
\hline Control for Age & $\checkmark$ & $\checkmark$ & $\checkmark$ & $\checkmark$ \\
\hline DHS Cluster FE & $\checkmark$ & $\checkmark$ & $\checkmark$ & $\checkmark$ \\
\hline Birth year FE & $\checkmark$ & $\checkmark$ & $\checkmark$ & $\checkmark$ \\
\hline Countries & 41 & 41 & 32 & 32 \\
\hline Clusters & 31878 & 31878 & 18561 & 18561 \\
\hline $\mathrm{N}$ & 395718 & 395718 & 120424 & 120424 \\
\hline
\end{tabular}

This table relates geographical connections to national leaders to educational attainment of DHS respondents. The dependent variable is the total years of education of a respondent at the time of the interview. The independent variable of interest are continuous variables that measure the share of years a respondent was connected to a national leader when she was between zero and twelve years (Model 1 and 3) and between five and twelve years (Model 2 and 4). To explore non-linear effects, we include a quadratic transformation of the variable measuring the share of treated years. All regressions include DHS cluster fixed effects (which implicitly control for country specific survey year fixed effects) and control for a respondent's age at the time of the DHS interview. Hypothesis tests are based on clustered standard errors at the level of individual surveys. 
Table 5: Connected LEAdERS AND EDUCATIONAL ATTAINMENT, ROBUSTNESS TESTS

\begin{tabular}{|c|c|c|c|c|c|c|c|c|c|c|}
\hline & \multicolumn{2}{|l|}{ Cubic age } & \multicolumn{2}{|c|}{$20 \mathrm{~km}$ buffer } & \multicolumn{2}{|c|}{$5 \mathrm{~km}$ buffer } & \multicolumn{2}{|c|}{ Aligned sample } & \multicolumn{2}{|c|}{ Post-treatment } \\
\hline & Women & Men & Women & Men & Women & Men & Women & Men & Women & Men \\
\hline & (1) & (2) & (3) & (4) & (5) & (6) & (7) & (8) & (9) & (10) \\
\hline \multirow[t]{2}{*}{ Connected leader, younger than 5} & -0.292 & 0.172 & -0.216 & 0.200 & -0.132 & 0.079 & -0.487 & 0.260 & -0.286 & 0.364 \\
\hline & $(0.273)$ & $(0.183)$ & $(0.228)$ & $(0.201)$ & $(0.330)$ & $(0.326)$ & $(0.336)$ & $(0.206)$ & $(0.337)$ & $(0.285)$ \\
\hline \multirow[t]{2}{*}{ Connected leader, years 5-12 } & -0.131 & $0.877^{* *}$ & -0.154 & 0.603 & 0.193 & $1.055^{*}$ & -0.386 & 0.949 ** & -0.050 & $1.093 * *$ \\
\hline & $(0.398)$ & $(0.377)$ & $(0.308)$ & $(0.367)$ & $(0.496)$ & $(0.544)$ & $(0.477)$ & $(0.395)$ & $(0.463)$ & $(0.423)$ \\
\hline \multirow[t]{2}{*}{ Connected leader, years $12-18$} & -0.203 & 0.097 & -0.260 & 0.153 & 0.027 & 0.847 & -0.543 & 0.067 & -0.210 & 0.255 \\
\hline & $(0.537)$ & $(0.407)$ & $(0.363)$ & $(0.362)$ & $(0.635)$ & $(0.637)$ & $(0.616)$ & $(0.438)$ & $(0.576)$ & $(0.458)$ \\
\hline \multirow[t]{2}{*}{ Connected leader, older than 18} & -0.321 & 0.519 & -0.248 & 0.227 & -0.445 & 0.861 & -1.002 & 0.521 & -0.361 & 0.619 \\
\hline & $(0.497)$ & $(0.523)$ & $(0.348)$ & $(0.474)$ & $(0.573)$ & $(0.719)$ & $(0.665)$ & $(0.577)$ & $(0.543)$ & $(0.563)$ \\
\hline \multirow[t]{2}{*}{ Five years after treatment } & & & & & & & & & -0.030 & 0.278 \\
\hline & & & & & & & & & $(0.266)$ & $(0.462)$ \\
\hline Control for Age & $\checkmark$ & $\checkmark$ & $\checkmark$ & $\checkmark$ & $\checkmark$ & $\checkmark$ & $\checkmark$ & $\checkmark$ & $\checkmark$ & $\checkmark$ \\
\hline DHS Cluster FE & $\checkmark$ & $\checkmark$ & $\checkmark$ & $\checkmark$ & $\checkmark$ & $\checkmark$ & $\checkmark$ & $\checkmark$ & $\checkmark$ & $\checkmark$ \\
\hline Birth year FE & $\checkmark$ & $\checkmark$ & $\checkmark$ & $\checkmark$ & $\checkmark$ & $\checkmark$ & $\checkmark$ & $\checkmark$ & $\checkmark$ & $\checkmark$ \\
\hline Countries & 41 & 32 & 41 & 32 & 41 & 32 & 32 & 32 & 41 & 32 \\
\hline Clusters & 31878 & 18561 & 31485 & 18336 & 32055 & 18624 & 16342 & 16342 & 31878 & 18561 \\
\hline $\mathrm{N}$ & 395718 & 120424 & 391133 & 119188 & 396985 & 120736 & 219425 & 107069 & 395718 & 120424 \\
\hline
\end{tabular}

Table 6: CONNECTED LEADERS AND EMPLOYMENT OUTCOMES

\begin{tabular}{|c|c|c|c|c|c|c|}
\hline & \multicolumn{3}{|l|}{ Women } & \multicolumn{3}{|l|}{ Men } \\
\hline & (1) & (2) & (3) & (4) & (5) & (6) \\
\hline \multicolumn{7}{|l|}{ Dep.Var: Years of education } \\
\hline \multirow{2}{*}{ Connected leader } & 0.007 & & & $0.060^{*}$ & & \\
\hline & $(0.018)$ & & & $(0.034)$ & & \\
\hline \multirow[t]{2}{*}{ Connected leader, younger than 12} & & 0.006 & & & $0.062 *$ & \\
\hline & & $(0.018)$ & & & $(0.033)$ & \\
\hline \multirow[t]{2}{*}{ Connected leader, older than 12} & & 0.016 & & & 0.046 & \\
\hline & & $(0.024)$ & & & $(0.046)$ & \\
\hline \multirow[t]{2}{*}{ Connected leader, younger than 5} & & & 0.011 & & & 0.054 \\
\hline & & & $(0.018)$ & & & $(0.038)$ \\
\hline \multirow[t]{2}{*}{ Connected leader, years 5-12 } & & & -0.017 & & & $0.081^{* *}$ \\
\hline & & & $(0.024)$ & & & $(0.039)$ \\
\hline \multirow[t]{2}{*}{ Connected leader, years $12-18$} & & & 0.019 & & & 0.083 \\
\hline & & & $(0.031)$ & & & $(0.062)$ \\
\hline \multirow[t]{2}{*}{ Connected leader, older than 18} & & & -0.006 & & & 0.017 \\
\hline & & & $(0.024)$ & & & $(0.049)$ \\
\hline Control for Age & $\checkmark$ & $\checkmark$ & $\checkmark$ & $\checkmark$ & $\checkmark$ & $\checkmark$ \\
\hline DHS Cluster FE & $\checkmark$ & $\checkmark$ & $\checkmark$ & $\checkmark$ & $\checkmark$ & $\checkmark$ \\
\hline Birth year FE & $\checkmark$ & $\checkmark$ & $\checkmark$ & $\checkmark$ & $\checkmark$ & $\checkmark$ \\
\hline Countries & 37 & 37 & 37 & 25 & 25 & 25 \\
\hline Clusters & 19635 & 19635 & 19635 & 9113 & 9113 & 9113 \\
\hline $\mathrm{N}$ & 161134 & 161134 & 161134 & 52595 & 52595 & 52595 \\
\hline
\end{tabular}


Table 7: CONNECTED LEADERS AND INDIVIDUAL OUTCOMES, VALUE OF ETHNIC CONNECTIONS

\begin{tabular}{|c|c|c|c|c|c|c|}
\hline \multirow[b]{3}{*}{ Connected leader } & \multicolumn{3}{|l|}{ Women } & \multicolumn{3}{|l|}{ Men } \\
\hline & (1) & (2) & (3) & (4) & (5) & (6) \\
\hline & $\begin{array}{l}-0.356 \\
(0.279)\end{array}$ & & & $\begin{array}{l}0.503^{\text {*** }} \\
(0.207)\end{array}$ & & \\
\hline Same ethnicity & $\begin{array}{l}0.071 \\
(0.071)\end{array}$ & $\begin{array}{l}0.083 \\
(0.072)\end{array}$ & $\begin{array}{l}0.089 \\
(0.071)\end{array}$ & $\begin{array}{l}0.083 \\
(0.078)\end{array}$ & $\begin{array}{l}0.087 \\
(0.078)\end{array}$ & $\begin{array}{l}0.073 \\
(0.076)\end{array}$ \\
\hline Connected leader $\times$ Same ethnicity & $\begin{array}{l}0.676^{* * * *} \\
(0.248)\end{array}$ & & & $\begin{array}{l}-0.481 \\
(0.503)\end{array}$ & & \\
\hline Connected leader, below 12 years & & $\begin{array}{l}-0.308 \\
(0.269)\end{array}$ & & & $\begin{array}{l}0.581^{* *} \\
(0.222)\end{array}$ & \\
\hline Connected leader, above 12 years & & $\begin{array}{l}-0.297 \\
(0.477)\end{array}$ & & & $\begin{array}{l}0.319 \\
(0.376)\end{array}$ & \\
\hline Connected leader, below 12 years $\times$ Same ethnicity & & $\begin{array}{l}0.410^{* * *} \\
(0.182)\end{array}$ & & & $\begin{array}{l}-0.714 \\
(0.503)\end{array}$ & \\
\hline Connected leader, younger than 5 & & & $\begin{array}{l}-0.259 \\
(0.279)\end{array}$ & & & $\begin{array}{l}0.274 \\
(0.195)\end{array}$ \\
\hline Connected leader, years 5-12 & & & $\begin{array}{l}-0.183 \\
(0.380)\end{array}$ & & & $\begin{array}{l}1.018^{* * * *} \\
(0.381)\end{array}$ \\
\hline Connected leader, years 12-18 & & & $\begin{array}{l}-0.169 \\
(0.554)\end{array}$ & & & $\begin{array}{l}0.177 \\
(0.417)\end{array}$ \\
\hline Connected leader, older than 18 & & & $\begin{array}{l}-0.336 \\
(0.506)\end{array}$ & & & $\begin{array}{l}0.538 \\
(0.538)\end{array}$ \\
\hline Connected leader, years 5-12 $\times$ Same ethnicity & & & $\begin{array}{l}1.529^{* * * *} \\
(0.267)\end{array}$ & & & $\begin{array}{l}-0.021 \\
(0.445)\end{array}$ \\
\hline Control for Age & $\checkmark$ & $\checkmark$ & $\checkmark$ & $\checkmark$ & $\checkmark$ & $\checkmark$ \\
\hline DHS Cluster FE & $\checkmark$ & $\checkmark$ & $\checkmark$ & $\checkmark$ & $\checkmark$ & $\checkmark$ \\
\hline Birth year FE & $\checkmark$ & $\checkmark$ & $\checkmark$ & $\checkmark$ & $\checkmark$ & $\checkmark$ \\
\hline Countries & 41 & 41 & 41 & 32 & 32 & 32 \\
\hline Clusters & 31878 & 31878 & 31878 & 18561 & 18561 & 18561 \\
\hline $\mathrm{N}$ & 395718 & 395718 & 395718 & 120424 & 120424 & 120424 \\
\hline
\end{tabular}


Table 8: CONNECTED LEADERS AND INDIVIDUAL OUTCOMES ACCORDING TO THE LEVEL OF DEMOCRACY

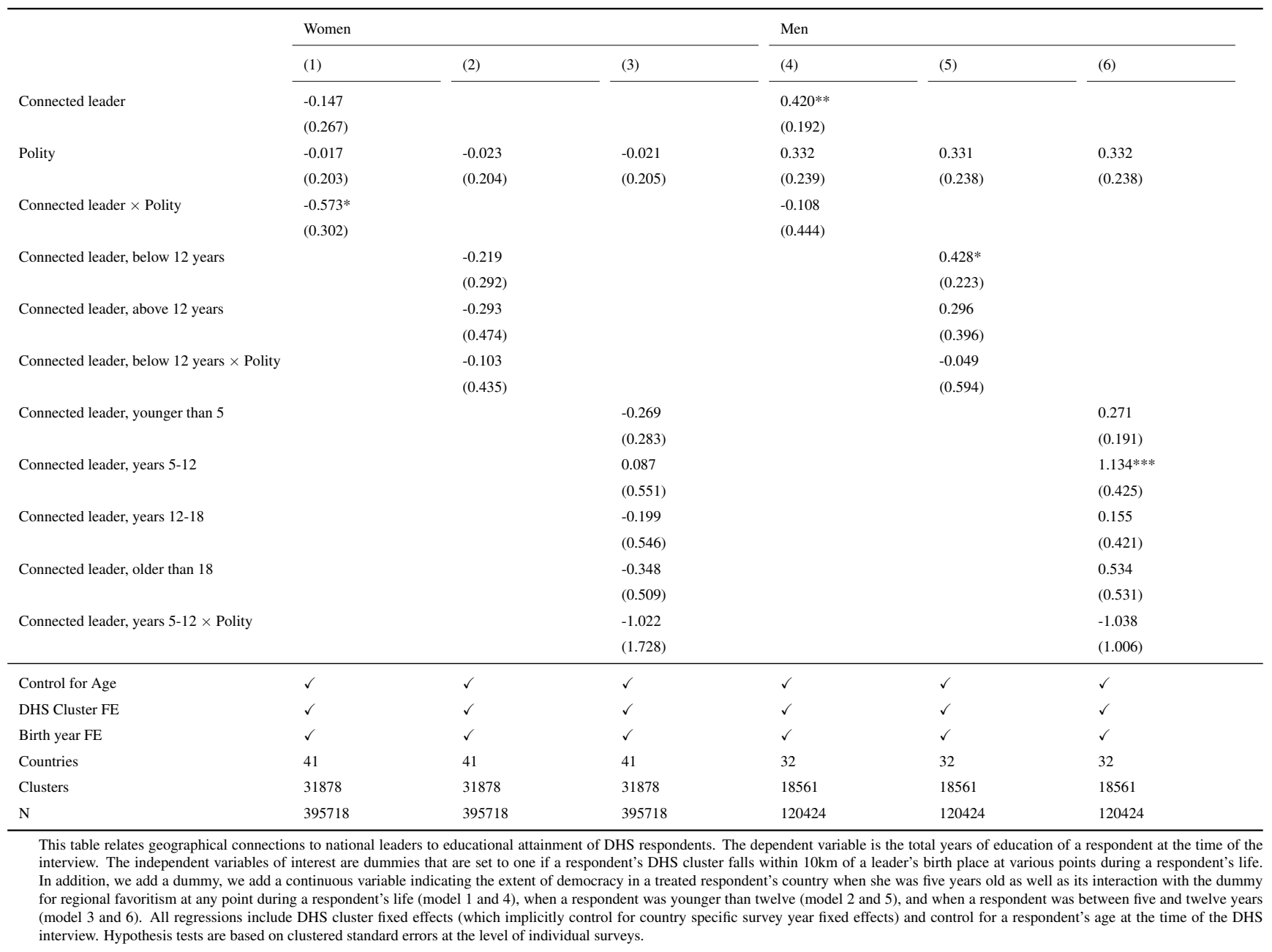




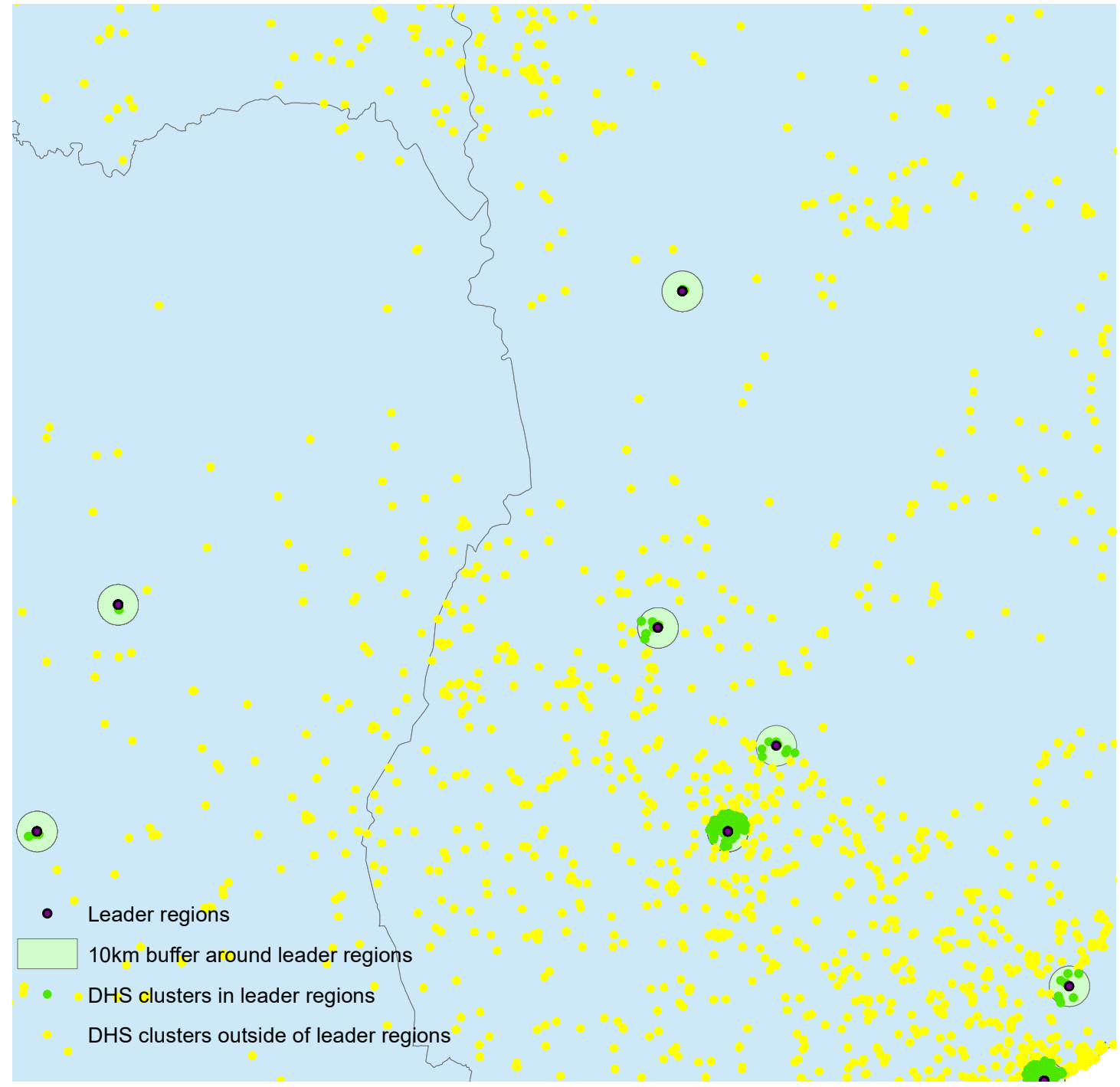

Figure 1: DHS clusters and national leaders' birthplaces in Africa. This figure shows the 10km buffers around leaders' birth regions (light green circles) and indicates treated (green dots) and untreated (yellow dots) DHS clusters. 


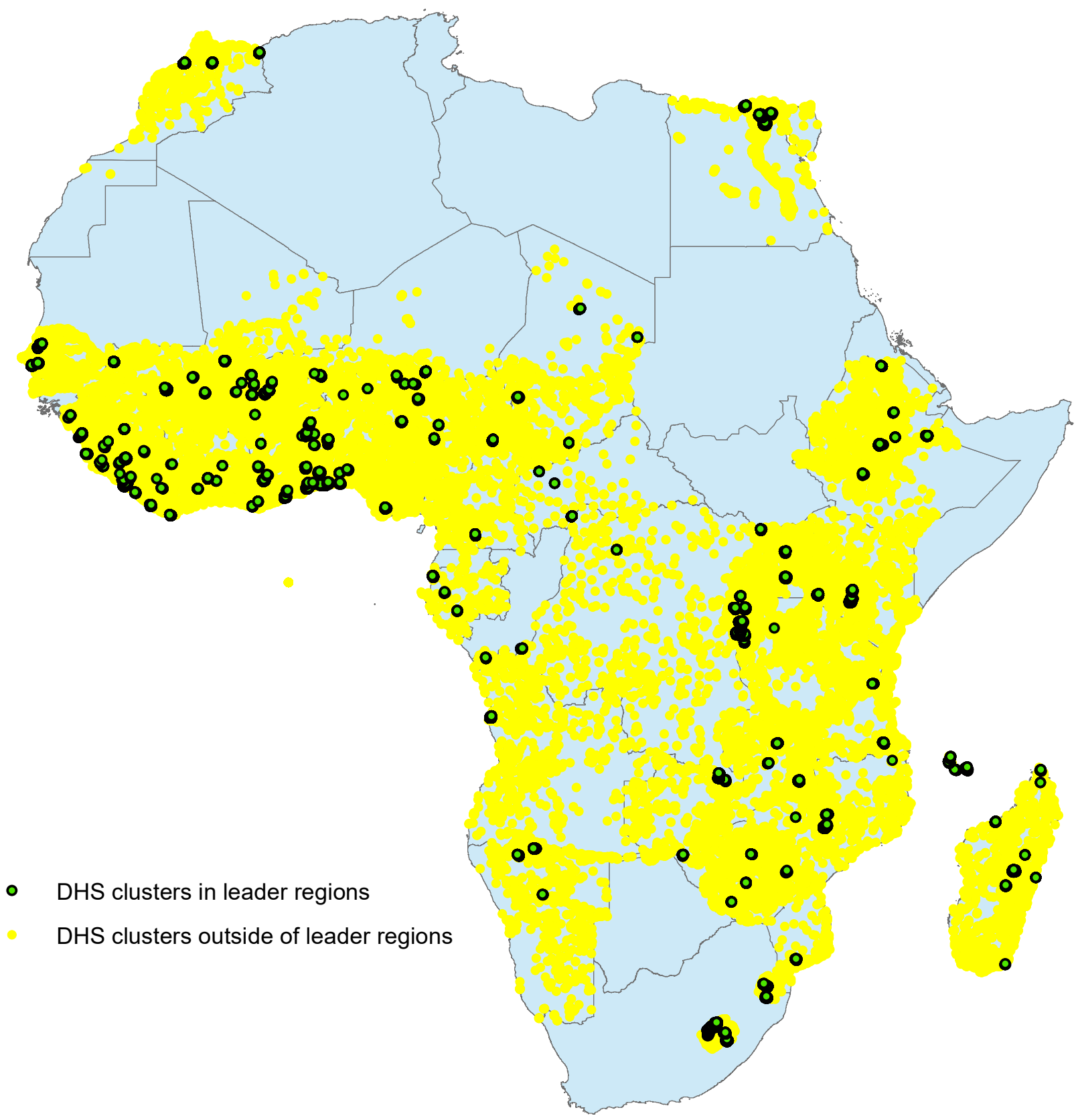

Figure 2: Treated and untreated DHS clusters in Africa. This figure shows all treated (green dots) and untreated (yellow dots) included in the main estimation sample. 


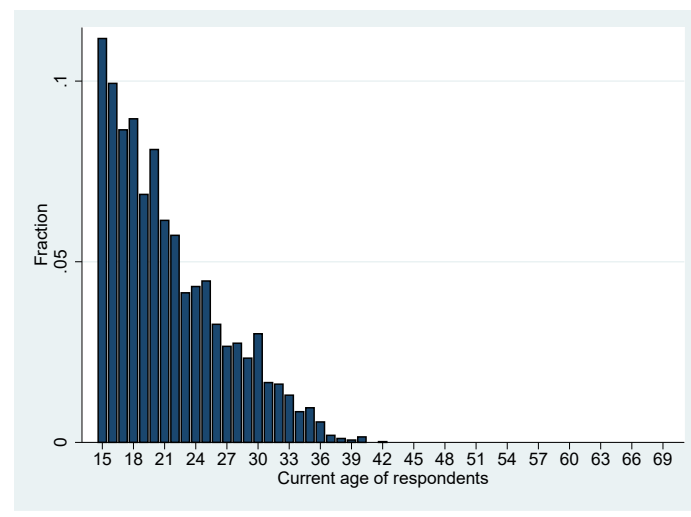

(a) Unconnected respondents in treated clusters

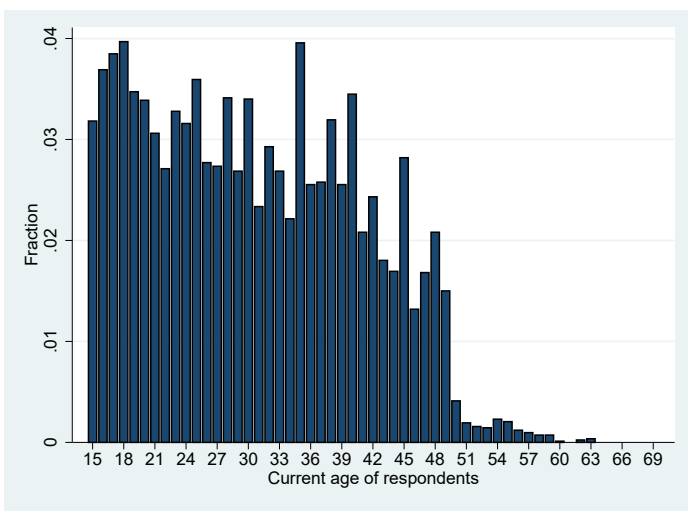

(b) Connected respondents in treated clusters

Figure 3: Age distribution of DHS respondents. This figure displays the age distribution of two subsamples of DHS respondents. Subfigure (a) shows the age distribution of those respondents who were never connected to a national leader in treated clusters. Subfigure (b) shows the age distribution of respondents who were connected at some point in their lives to a national leader.

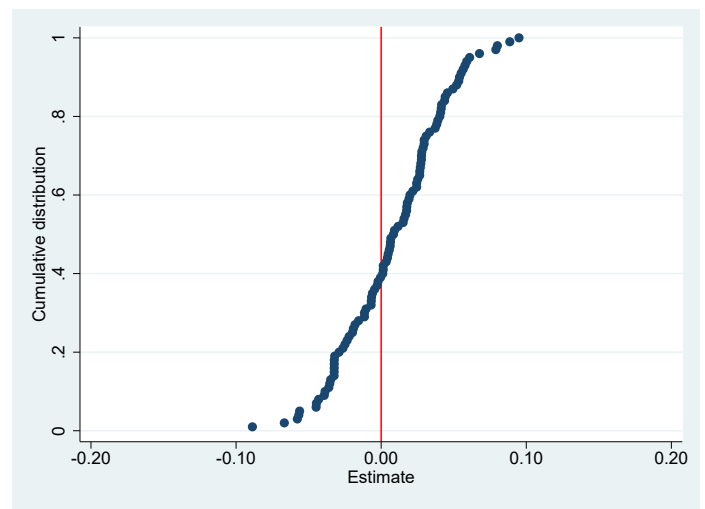

(a) Women

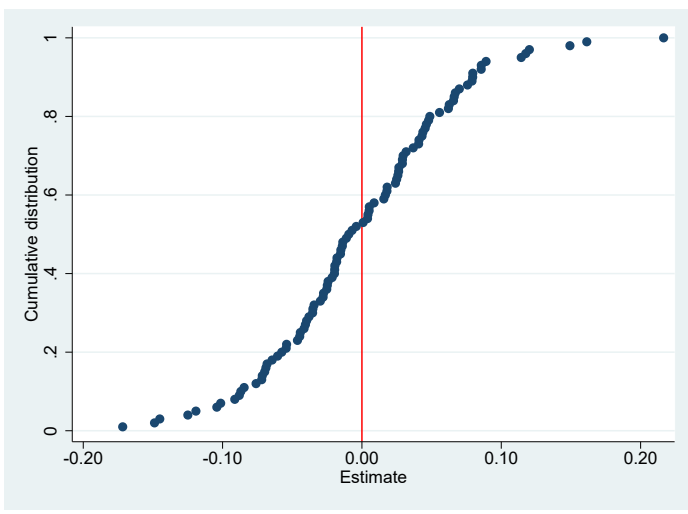

(b) Men

Figure 4: Placebo regressions for women: connected leaders and education. This figure collects placebo regressions results regarding the effect of a connected leader on educational attainment. For this, we rely on a sample that excludes the 914 treated DHS clusters. Instead, we randomly assign 8,264 individuals in untreated DHS clusters to the treatment group and re-estimate the regressions reported in Table 3, column 1 and 4 . We estimate 100 such placebo regressions and plot the cumulative distribution of the coefficient estimates (blue dots) in the above figures. 
Download ZEW Discussion Papers from our ftp server:

http://ftp.zew.de/pub/zew-docs/dp/

or see:

https://www.ssrn.com/link/ZEW-Ctr-Euro-Econ-Research.html

https://ideas.repec.org/s/zbw/zewdip.html

$$
\text { // }
$$

IMPRINT

ZEW - Leibniz-Zentrum für Europäische Wirtschaftsforschung GmbH Mannheim

ZEW - Leibniz Centre for European

Economic Research

L 7,1 68161 Mannheim · Germany

Phone +49621 1235-01

info@zew.de·zew.de

Discussion Papers are intended to make results of ZEW research promptly available to other economists in order to encourage discussion and suggestions for revisions. The authors are solely responsible for the contents which do not necessarily represent the opinion of the ZEW. 